\title{
Low back pain in older adults - the need for specific outcome and psychometric tools
}

\section{Arnold Y Wong' \\ Dino Samartzis ${ }^{2}$}

'Department of Rehabilitation Sciences, Faculty of Health and Social Sciences, The Hong Kong Polytechnic University, Hung Hom, Hong Kong, Special Administrative Region of China; ${ }^{2}$ Department of Orthopaedics and Traumatology, The University of Hong Kong, Pokfulam, Hong Kong, Special Administrative Region of China
Correspondence: Arnold YL Wong Room ST5 12, Department of Rehabilitation Sciences, Faculty of Health and Social Sciences, The Hong Kong Polytechnic University, Hung Hom, Hong Kong, Special Administrative Region of China

Tel +852 2766 674l

Email arnold.wong@polyu.edu.hk

\author{
This article was published in the following Dove Press journal: \\ Journal of Pain Research \\ 8 November 2016 \\ Number of times this article has been viewed
}

The average human life expectancy has increased significantly worldwide due to advances in medicine, health care delivery, and technology over recent years. ${ }^{1}$ The United Nations has estimated that the proportion of older individuals aged 60 or over in the world will increase threefold by the year $2050 .{ }^{2}$ However, the fast growth of the aging population is accompanied by global increase in the incidence of low back pain (LBP) complaints and associated medical costs. ${ }^{3}$

The most prevalent health condition in older adults that leads to functional limitations and disability is LBP. ${ }^{3}$ Several population-based studies have estimated that the 1-year prevalence of LBP in community-dwelling seniors ranged from $13 \%$ to $50 \%$. ${ }^{4,5}$ Importantly, older adults are more prone to experience disabling LBP compared to younger individuals. ${ }^{6}$ Williams et $\mathrm{al}^{7}$ noted that seniors aged 80 years or older had a 3 times higher odds of experiencing high-intensity LBP than those aged 50-59 years. Since high-intensity LBP is associated with unfavorable treatment outcomes and disability, ${ }^{8}$ seniors with LBP usually have poor functional ability. ${ }^{9}$ Furthermore, since the prevalence of chronic LBP also increases with age, ${ }^{10,11}$ the prevalence of chronic LBP in adults aged 70 years or older has been estimated to be as high as $58 \% .^{12}$

Given the high prevalence and multifactorial causes of LBP in older people, the assessments and treatments of LBP are very challenging. A survey highlights that less than half of primary care physicians are very confident in diagnosing contributors of chronic LBP in seniors. ${ }^{9}$ Causes of LBP in older adults may differ from those in a younger population. Aside from nonspecific or mechanical LBP, older people may experience LBP secondary to osteoporotic spine fractures, tumors/cancers, vertebral osteomyelitis, and visceral diseases. ${ }^{13}$ Additionally, risk factors (such as age, ${ }^{14}$ psychosocial factors, ${ }^{11,15}$ and comorbidities ${ }^{12}$ ) for chronic LBP in older adults may vary in comparison to the younger population, which may further compound their quality of life, ${ }^{16}$ risk of falls, ${ }^{5}$ and management outcomes. Imperatively, since clinicians' low confidence in diagnosing patients with LBP may lead to overreliance on medical imaging or delay in proper LBP management, it is necessary for primary care providers to acquire enhanced understanding of LBP assessments in geriatric patients.

Comprehensive history taking and physical examinations are essential for making differential diagnoses for seniors with LBP. Specifically, the history of present illness should focus on the nature, location, severity, onset, and chronicity of LBP. The aggravating and easing factors of LBP should be asked for, to help differentiate 
between mechanical and nonmechanical LBP. Potential "red flags" (eg, fever, night pain, radiating pain/numbness, general malaise, weight loss, colicky/abdominal pain, and urinary and/or bowel incontinence) should be questioned to rule out specific pathology. ${ }^{17,18}$ Since physical, mental, and psychological comorbidities ${ }^{13,19,20}$ can adversely affect LBP prognosis in seniors, the past medical history of patients should also be taken.

Although many self-reported LBP-related questionnaires have been developed to evaluate the impacts of LBP on working-age patients, only a few of them (eg, modified Oswestry disability index and Quebec Back Pain Disability questionnaires) have been validated in seniors. ${ }^{21}$ Because the physical and psychosocial challenges encountered by community-dwelling/institutionalized older adults significantly differ from those faced by young adults, appropriate LBP outcome measures should be developed/adopted to evaluate age-specific LBP conditions of geriatric patients.

Aside from self-reported measurements, physical examinations of the lumbar region are commonly used to identify spinal anomalies, while neurological examinations (eg, reflex, muscle strength, sensation, or straight leg raising) are applied to evaluate neurological deficits. Further, physical examinations can be used to diagnose sacroiliac joint syndrome, fibromyalgia, myofascial pain, or hip problems without using medical imaging. ${ }^{16}$ If there are signs of sphincter dysfunction, saddle anesthesia, acute neurologic deterioration, or nerve compression, further imaging and emergency surgical managements are indicated. Similarly, patients with unrelenting pain, fever, shock, diaphoresis, and a recent acute trauma may require additional investigations to exclude specific pathology. Since many geriatric patients with LBP experience musculoskeletal comorbidity, successful identification and treatment of concomitant disorders can reduce patients' long-term disability and health-related quality of life. ${ }^{16}$

In addition, performance-based examinations and falls risk assessments are extremely important for seniors with LBP. ${ }^{22}$ For example, the Short Physical Performance Battery can be adopted to determine functional deficits in seniors through evaluating their walking speed, standing balance, and sit-to-stand ability. Performance-based falls risk assessments can also be used to identify high-risk individuals for fall prevention interventions.

As it is common to find degenerative changes/anomalies on lumbar medical images of asymptomatic seniors, imaging is not indicated at the initial assessments of seniors with LBP except for those with acute trauma or symptoms of suspected pathology. ${ }^{17,18}$ If patients fail to respond to conservative treatments, imaging may be indicated to exclude serious pathology. Generally, it is necessary to consider imaging findings, clinical presentations, and other clinical test results together to make a diagnosis.

While an increasing number of geriatric studies have evaluated the effectiveness of various LBP treatments for seniors, ${ }^{23}$ the psychometric properties of many self-reported LBP outcome measures have not been validated in the older population. To effectively monitor LBP progression in these patients, validated LBP outcome measures with good psychometric properties should be developed/used.

Although research has shown that working-age patients with LBP may be characterized by reduced static or dynamic morphometry of lumbar multifidus as measured by ultrasonography or axial magnetic resonance imaging (MRI), ${ }^{24-26}$ it remains unclear whether geriatric patients with LBP display similar characteristics. Since sarcopenia increases with advancing age, ${ }^{27}$ seniors with LBP may be affected by both age- and LBP-related changes in lumbar multifidus. Therefore, future research is warranted to examine if ultrasonography or MRI can detect lumbar multifidus deficits in older patients with LBP, which may guide treatments.

Additionally, the importance of the sagittal spinopelvic alignment or balance has taken center stage in recent years, ${ }^{28}$ especially its role in skeletal health and LBP profiles. Agespecific spinal alignment/balance parameters and their implications on LBP generation or prediction should be better understood in order to establish effective management algorithms. Importantly, in the age of globalization, ethnic and cultural variations as well as a genetic predisposition may play a role in pain perception and/or reporting. Having a better understanding of these underpinnings in relation to the geriatric population may have direct implications upon prevention, care, and patient outcomes.

Overall, although LBP is prevalent among older people, little is known about the trajectories of LBP, determinants of chronic LBP, and the effectiveness of LBP interventions in older adults. Given the multifactorial causes of LBP and age-related physical and psychological changes in older people, primary care providers should adopt comprehensive subjective and physical examinations to make diagnoses. Although conventional imaging (eg, T2-weighted MRI, plain radiographs) plays little role in patients without pathological signs and symptoms, new imaging techniques may provide useful information to identify the pain-generating source and to assist clinical decision-making. Such advances coupled with discoveries in biomarkers and more refined assessments of the aging population may play a significant role in deriving 
novel therapeutics that adopt a more personalized or precision approach toward LBP management.

\section{Disclosure}

The authors report no conflicts of interest in this work.

\section{References}

1. Tse MM, Pun SP, Benzie IF. Pain relief strategies used by older people with chronic pain: an exploratory survey for planning patient-centred intervention. J Clin Nurs. 2005;14:315-320.

2. Department of Economic and Social Affairs United Nations. World Population Ageing 2009. New York: United Nations Publication; 2010

3. Prince MJ, Wu F, Guo Y, et al. The burden of disease in older people and implications for health policy and practice. Lancet. 2015;385: 549-562.

4. Leopoldino AAO, Diz JBM, Martins VT, et al. Prevalence of low back pain in older Brazilians: a systematic review with meta-analysis. Rev Bras Reumatol Engl Ed. 2016;56:258-269.

5. Woo J, Leung J, Lau E. Prevalence and correlates of musculoskeletal pain in Chinese elderly and the impact on 4-year physical function and quality of life. Public Health. 2009;123:549-556.

6. Dionne CE, Dunn KM, Croft PR. Does back pain prevalence really decrease with increasing age? A systematic review. Age Ageing. 2006;35:229-234.

7. Williams JS, Ng N, Peltzer K, et al. Risk factors and disability associated with low back pain in older adults in low- and middle-income countries. Results from the WHO Study on Global AGEing and Adult Health (SAGE). PLoS One. 2015;10:e0127880.

8. Reid MC, Williams CS, Gill TM. Back pain and decline in lower extremity physical function among community-dwelling older persons. J Gerontol A Biol Sci Med Sci. 2005;60:793-797.

9. Cayea D, Perera S, Weiner DK. Chronic low back pain in older adults: what physicians know, what they think they know, and what they should be taught. J Am Geriatr Soc. 2006;54:1772-1777.

10. Di Iorio A, Abate M, Guralnik JM, et al. From chronic low back pain to disability, a multifactorial mediated pathway: The InCHIANTI Study. Spine. 2007;32:E809-E815.

11. Jiménez-Sánchez S, Fernández-de-las-Peñas C, Carrasco-Garrido P, et al. Prevalence of chronic head, neck and low back pain and associated factors in women residing in the Autonomous Region of Madrid (Spain). Gaceta Sanitaria. 2012;26:534-540.

12. Jacobs JM, Hammerman-Rozenberg R, Cohen A, Stessman J. Chronic back pain among the elderly: prevalence, associations, and predictors Spine. 2006;31:E203-E207.
13. Jones LD, Pandit H, Lavy C. Back pain in the elderly: a review. Maturitas. 2014;78:258-262.

14. Kim W, Jin YS, Lee CS, et al. Relationship between the type and amount of physical activity and low back pain in Koreans aged 50 years and older. PM R. 2014;6:893-899.

15. Hartvigsen J, Christensen K, Frederiksen H. Back and neck pain exhibit many common features in old age: a population-based study of 4,486 Danish Twins 70-102 years of age. Spine. 2004;29:576-580.

16. Weiner DK, Sakamoto S, Perera S, Breuer P. Chronic low back pain in older adults: prevalence, reliability, and validity of physical examination findings. J Am Geriatr Soc. 2006;54:11-20.

17. Karppinen J, Shen FH, Luk KDK, Andersson GBJ, Cheung KMC, Samartzis D. Management of degenerative disk disease and chronic low back Pain. Orthop Clin North Am. 2011;42:513-528.

18. Shen FH, Samartzis D, Andersson GBJ. Nonsurgical management of acute and chronic low back pain. J Am Acad Orthop Surg. 2006;14:477-487.

19. Reid MC, Williams CS, Concato J, Tinetti ME, Gill TM. Depressive symptoms as a risk Factor for disabling back pain in communitydwelling older persons. J Am Geriatr Soc. 2003;51:1710-1717.

20. Karp JF, DiNapoli EA, Wetherell J, et al. Deconstructing chronic low back pain in the older adult — step by step evidence and expert-based recommendations for evaluation and treatment: part IX: anxiety. Pain Med. 2016;17:1423-1435.

21. Hicks GE, Manal TJ. Psychometric properties of commonly used low back disability questionnaires: Are they useful for older adults with low back pain? Pain Med. 2009;10:85-94.

22. Coyle PC, Velasco T, Sions JM, Hicks GE. Lumbar mobility and performance-based function: an investigation in older adults with and without chronic low back Pain. Pain Med. Epub June 26, 2016.

23. Leonhardt C, Kuss K, Becker A, et al. Graded exposure for chronic low back pain in older adults. $J$ Geriatr Phys Ther. Epub April 7, 2016.

24. Wallwork TL, Stanton WR, Freke M, Hides JA. The effect of chronic low back pain on size and contraction of the lumbar multifidus muscle. Man Ther. 2009;14:496-500.

25. Wong AY, Parent EC, Funabashi M, Stanton TR, Kawchuk GN. Do various baseline characteristics of transversus abdominis and lumbar multifidus predict clinical outcomes in nonspecific low back pain? A systematic review. Pain. 2013;154:2589-2602.

26. Wong AY, Parent EC, Funabashi M, Kawchuk GN. Do changes in transversus abdominis and lumbar multifidus during conservative treatment explain changes in clinical outcomes related to nonspecific low back pain? A systematic review. J Pain. 2014;15:377.e1-35.

27. Morley JE. Sarcopenia in the elderly. Fam Pract. 2012;29(Suppl 1):i44-i48.

28. Chaléat-Valayer E, Mac-Thiong JM, Paquet J, Berthonnaud E, Siani F, Roussouly P. Sagittal spino-pelvic alignment in chronic low back pain Eur Spine J. 2011;20(Suppl 5):634-640.

Dove Medical Press encourages responsible, free and frank academic debate. The content of the Journal of Pain Research 'Editorial' section does not necessarily represent the views of Dove Medical Press, its officers, agents, employees, related entities or the Journal of Pain Research editors. While all reasonable steps have been taken to confirm the content of each Editorial, Dove Medical Press accepts no liability in respect of the content of any Editorial, nor is it responsible for the content and accuracy of any Editorial.

\section{Journal of Pain Research}

\section{Publish your work in this journal}

The Journal of Pain Research is an international, peer reviewed, open access, online journal that welcomes laboratory and clinical findings in the fields of pain research and the prevention and management of pain. Original research, reviews, symposium reports, hypothesis formation and commentaries are all considered for publication.

\section{Dovepress}

The manuscript management system is completely online and includes a very quick and fair peer-review system, which is all easy to use. Visit http://www.dovepress.com/testimonials.php to read real quotes from published authors. 